CARACTERIZAÇÃO, INSERÇÃO E RESISTÊNCIA DE MUARES

\author{
COSTA, Ana Paula Borges da ${ }^{1}$ \\ PACHECO, Paulo Santana ${ }^{2}$
}

\begin{abstract}
RESUMO: Os muares são animais híbridos provenientes do cruzamento entre a fêmea equina (Equus caballus) e o macho asinino (Equus asinus). São animais rústicos e resistentes, e muito utilizados em trabalhos de tração. Os muares tiveram grande importância no Brasil na era colonial no transporte de gêneros alimentícios e outras mercadorias, principalmente no interior do país. Há um grande senso empírico de que os muares são animais mais resistentes do que os equinos e mais indicados para provas de resistência de baixa intensidade e longa duração, mas poucos dados científicos a respeito do assunto podem ser encontrados. Devido a esse fato há uma tendência crescente de se criar muares em detrimento de equinos, e o avanço desse setor em relação à seleção genética, têm feito da criação de muares um nicho de negócio bastante rentável. Análises de constituintes séricos sanguíneos de muares e equinos podem ser capazes de identificar qual espécie animal é mais resistente ao exercício físico. Os muares atualmente participam do chamado "agronegócio do cavalo", que movimenta grande valor econômico no país e gera muitos empregos diretos e indiretos. As enzimas lactato desidrogenase (LDH) e creatina quinase (CK) podem revelar se equinos e muares apresentam o mesmo desgaste frente ao exercício físico ou não. Devido ao exposto o presente trabalho tem como objetivo caracterizar os muares em relação aos equinos, descrever sua resistência e elucidar sua inserção no agronegócio atual.
\end{abstract}

Palavras-chave: Equídeos. Exercício físico. Mulas. Mercado equino.

\title{
CHARACTERIZATION, INSERTION AND RESISTANCE OF MULES AND DONKEYS
}

SUMMARY: Mules and donkeys are hybrid animals from the cross between the equine female (Equus caballus) and the male asinine (Equus asinus). They are rustic and resistant animals, and much used in traction works. The mules had great importance in Brazil in the colonial time in the transportation of foodstuffs and other goods, mainly in the countryside. There is a great empirical sense that mule animals are more resistant than equines and are best suited for low intensity and long duration resistance tests, but few scientific data on the subject can be found. Due to this fact there is a growing tendency to breed mules to the detriment of equines, and the advancement of this sector in relation to genetic selection, have made mule breeding a very profitable niche business. Analysis of serum blood constituents of mules and horses may be able to identify which animal species is more resistant to exercise. The mules currently participate in the so-called "agribusiness of the horse", which moves great economic value in the country and generates many direct and indirect jobs. The enzymes lactate dehydrogenase (LDH) and creatine kinase (CK) may reveal whether equines and mules present the same wear versus physical exercise or not. Due to the above the present work has the objective to characterize the mule in relation to the equines, to describe its resistance and to elucidate its insertion in the current agribusiness.

Keywords: Equidae. Physical exercise. Mules. Equine market.

\section{INTRODUÇÃO}

A relação do homem com os equídeos existe desde tempos muito remotos. Em tempos pré-históricos os animais domésticos já acompanhavam o homem, na sua vida e no

\footnotetext{
${ }^{1}$ Graduada em zootecnia, acadêmica no Mestrado em Desenvolvimento Rural Sustentável na UFG.

${ }^{2}$ Prof. Adjunto Departamento de Zootecnia - UFSM - Dr. em Ciência Animal, UFG (UFG),2007-Pós-doutorado na UFG, 2008. Linha de Pesquisa: Estatística/ Melhoramento Animal
} 
estabelecimento de sua civilização. Data da "Idade do Bronze" o relacionamento do homem com o cavalo (TORRES, 1981). Até o advento do motor de explosão no início do século XX, os equídeos constituíam ferramenta indispensável a todos os países para transporte, condução de lavouras e mobilidade dos exércitos. Devido a isso, havia grande preocupação dos governos em incentivar sua criação para garantir a produção, inclusive de alimentos, sua distribuição, viagens por vias terrestres, defesa de fronteiras, dentre outras funções. Mesmo com o surgimento da máquina a vapor, continuou-se o interesse e necessidade pela utilização desses animais (TORRES;JARDIM, 1992).

O Brasil possuía aproximadamente 5.175.489 estabelecimentos rurais, de acordo com o último CENSO Agropecuário realizado, em 2006. Desse total, 1.273.319 ainda utilizavam força de tração animal, e 591.421, utilizavam força de tração animal e mecânica (IBGE, 2006). Isso levar a crer que a necessidade de animais de trabalho nesses locais ainda seria considerável, visto que um equino ou muar é mais maleável e mais barato do que implementos agrícolas. Tratandose de espécies facilmente adaptáveis a condições de clima e manejos diversos, encontram-se disseminadas na maioria dos países, variando-se a raça dos animais que são melhores adaptadas às condições locais de cada região.

O Brasil possui o maior rebanho de equinos na América Latina e o terceiro mundial. Somados aos muares e asininos totalizam 8 milhões de cabeças, movimentando R $\$ 7,3$ bilhões, somente com a produção de cavalos. O rebanho envolve mais de 30 segmentos, distribuídos entre insumos, criação e destinação final e compõe a base do chamado Complexo do Agronegócio Cavalo, responsável pela geração de 3,2 milhões de empregos diretos e indiretos (BRASIL, 2016).

Desde que o ser humano estabeleceu vínculo com os equídeos, tanto em guerras quanto no cultivo da terra, até os dias atuais esses animais destacam-se no aspecto social, nas atividades de esportes e lazer, assim como na equoterapia para tratamento de portadores de dificuldades na área cognitiva, psicomotora e sócio afetiva (LIMA et al., 2006).

Quando é mencionado o termo "Equídeos", estão incluídos nesse grupo tanto os equinos (Equus caballus) quanto os muares, animais híbridos provenientes do cruzamento entre a fêmea equina e o jumento (Equus asinus). Há um grande senso empírico de que os muares são animais mais resistentes do que os equinos por agruparem características positivas das duas espécies progenitoras. O muar é um animal adaptado ao transporte de cargas, tendo sido muito utilizado até o começo do século XX, principalmente em locais de topografia acidentada, como parte do estado de Goiás. Diante de todo o exposto, objetivou-se por meio desta revisão, caracterizar e relatar a inserção e importância dos muares na sociedade atual e abordar sobre a resistência desses animais. 


\section{REVISÃO DA LITERATURA}

O processo de domesticação dos animais, de acordo com as teorias existentes, se deu no instante em que o ser humano decidiu estabelecer-se num determinado território, originando o sedentarismo e à prática da agropecuária, visando à produção de alimentos agricultáveis e de origem animal e produção de peles que protegiam contra os períodos mais frios do ano. Nesse momento ocorreu também a utilização de animais em trabalhos de tração e expansão territorial. Foi a partir daí que os equídeos se tornaram essenciais ao ser humano, e são largamente úteis até hoje como animais de esporte, trabalho e lazer (FARIA et al., 2014).

\section{Origem e histórico dos equídeos}

De acordo com Lima et al. (2006), diferentemente da maioria das espécies de animais a evolução dos equídeos pôde ser facilmente estudada pelo descobrimento de vários registros fósseis, e de acordo com os mesmos, o ancestral do cavalo surgiu na América durante a era cenozóica há aproximadamente de 60 milhões de anos. O primeiro antepassado do cavalo moderno é conhecido como Eohippus, tinha porte muito pequeno em relação ao cavalo moderno, media por volta de 35 centímetros de altura e possuía o dorso arqueado.

A espécie passou por várias fases de evolução, como mostra a figura 1, até resultar no surgimento do Equus na segunda metade da era do gelo. O Equus caballus migrou da América do Norte para outras partes do mundo através das ligações terrestres entre os continentes que existiam. Porém, ao final da era do gelo, desfez-se a ligação por terra entre a Ásia e a América, região do atual Estreito de Bering, e os cavalos na América ficaram isolados dos demais cavalos do mundo. Todavia, há cerca de 8.000 anos esses animais foram extintos do continente americano, e as causas desse fato não são conhecidas. Nessa época, o gênero Equus distribuía-se da seguinte forma: cavalos na Europa e Ásia, asnos no norte da África e zebras no sul da África (LIMA et al., 2006). 
Figura 1. Evolução do Eohippus até o Equus caballus

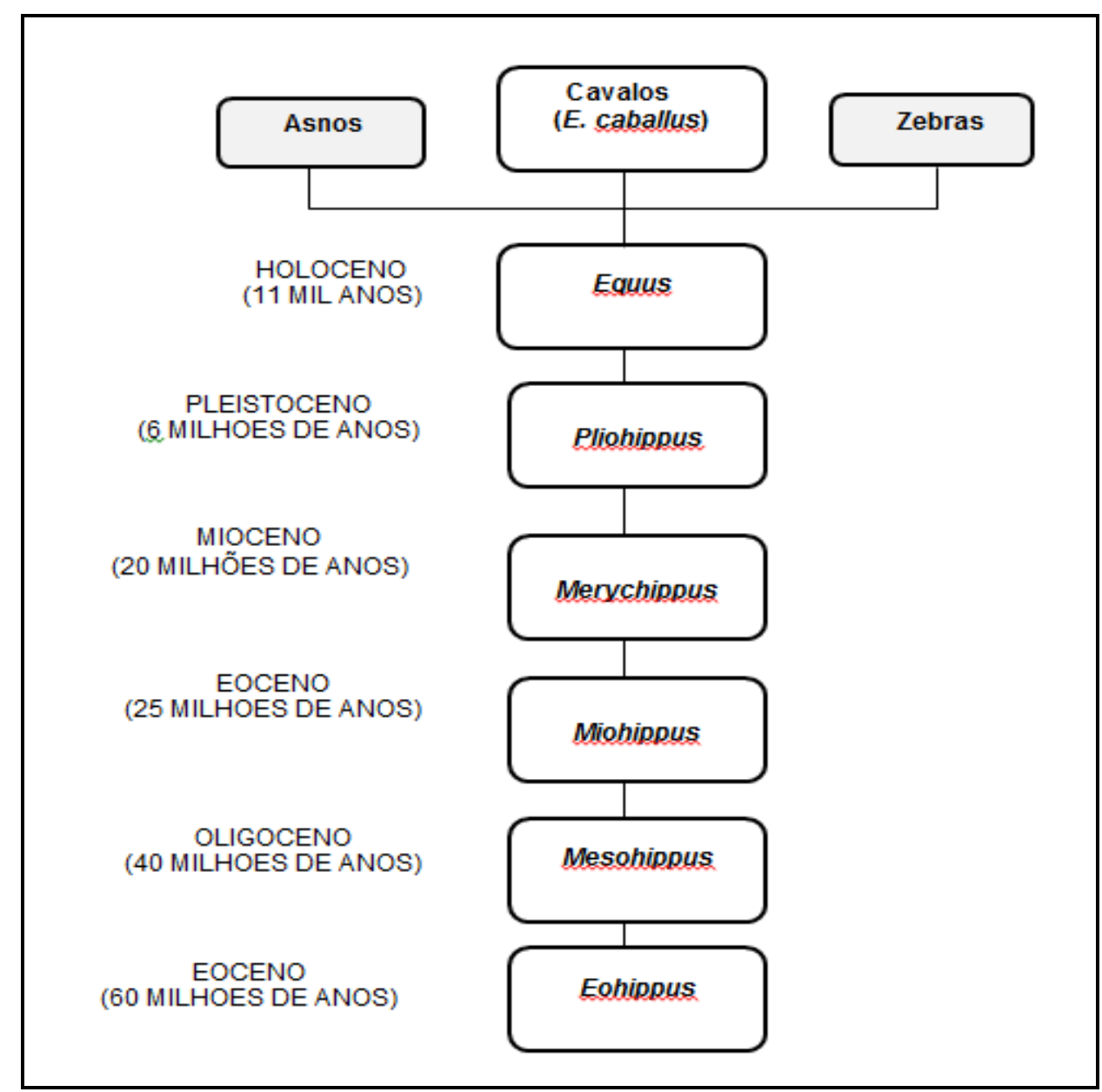

Fonte: Adaptado de Lima et al. (2006).

\section{Chegada dos equídeos nas Américas e no Brasil}

De acordo com Lima et al. (2006) a introdução dos equídeos na América do Sul se deu pelo Peru e Colômbia no ano de 1532. Dois anos mais tarde, 100 cavalos foram introduzidos na Argentina, e em 1535 ocorreu a entrada de mais equídeos no continente americano, pelo Chile e Venezuela. D. Alvar Nuñes Cabeza de Vaca em 1541 levou uma tropa de cavalos para as colônias espanholas, atravessando o território brasileiro (Paraná e Santa Catarina). Juntamente com os animais trazidos para a Argentina, parte desses animais contribuiu para o início da tropa no sul do Brasil.

De acordo com o mesmo autor mencionado anteriormente, pode ser que os primeiros equídeos destinados para utilização no Brasil tenham chegado em 1534, quando D. Ana Pimentel trouxe para a colônia vários animais domésticos, provenientes das ilhas da Madeira e das Canárias. Houve também a contribuição do donatário da Capitânia de Pernambuco, que começou a criação de animais domésticos no nordeste brasileiro. A chegada de cavalos no Brasil só teve registro oficial em 1549, ano em que Tomé de Souza, primeiro governador-geral, ordenou a vinda de alguns animais, de Cabo Verde para a Bahia. Dessa forma, nos primeiros anos do Brasil 
Colônia, a criação de equídeos, juntamente aos bovinos, foi iniciada formalmente, e seria primordial para a formação do Brasil.

Desde então, os equídeos se tornaram essenciais para a evolução do país, e indispensáveis para diversos trabalhos. De acordo com a FAO, a população mundial de equídeos foi estimada em 2008, em 113.473.522 cabeças, sendo 58.770.171 equinos, 43.496.677 asininos e 11.206.674 muares, e está distribuída nos continentes da seguinte maneira: África, com 4.519.216 cab. (7,7\%); América, com 33.594.119 cab. (57,2\%); Ásia, com 13.870.140 cab. (23,6\%); Europa, com 6.374.740 cab. (10,8\%); e Oceania, com 411.956 cab. (0,7\%), sendo evidente a concentração da produção e utilização dos equinos nas Américas (FAO, 2008).

\section{Dispersão dos muares pelo território nacional}

O efetivo de muares, no ano de 2011, foi de 1.269 milhão de cabeças, apresentando leve queda percentual em relação ao rebanho registrado em 2010. O Estado da Bahia participa com 21,6\% do efetivo nacional, seguido pelos Estados de Minas Gerais $(12,4 \%)$ e do Pará $(8,3 \%)$ (IBGE, 2011). A tabela 1 mostra o efetivo do rebanho equino no Brasil.

Tabela 1. Efetivo rebanho equino no Brasil e principais estados produtores

\begin{tabular}{ccc}
\hline Estado & Total rebanho & $\begin{array}{c}\text { Percentual rebanho } \\
\text { nacional (\%) }\end{array}$ \\
\hline Minas Gerais & 800.108 & 14,56 \\
\hline Bahia & 598.326 & 10,88 \\
\hline Goiás & 452.965 & 8,24 \\
\hline Rio Grande do Sul & 438.390 & 7,97 \\
\hline São Paulo & 380.333 & 6,92 \\
\hline Brasil & 5.496 .817 & 100 \\
\hline
\end{tabular}

Fonte: Adaptado de Vieira et al. (2015)

De acordo com Suprinyak (2008), a movimentação do Brasil do século 19 se deu em torno dos muares. Após a introdução desses animais na estrutura econômica brasileira durante o período colonial, os muares se tornaram o meio de transporte por excelência das regiões nãolitorâneas do Brasil imperial. As culturas do café e da cana-de-açúcar dependeram de maneira funcional dos serviços das tropas, tanto para o escoamento da produção, quanto para o abastecimento regional com gêneros de outras localidades.

Lima et al. (2006) explica como se deu o protagonismo desses animais no interior do Brasil. Na época do Brasil colônia e economia era baseada em duas principais atividades; a açucareira e a criatória, visto que a criação de bovinos era sempre associada às de tropas de equídeos para a lida. Houve um fator determinante para a ocupação territorial; visto que na época não existiam maneiras de se dividirem as propriedades, pois ainda não existiam cercas, surgiram 
conflitos entre agricultores, que tinham as lavouras invadidas por animais, e os criadores. Devido a esses desgastes o governo português proibiu a criação de rebanhos onde se localizavam as lavouras. Assim, a criação de animais foi forçada para o interior do país. Com o início do ciclo da mineração no interior do Brasil, se deu a necessidade de abastecer os núcleos mineradores, o que reforçou a interiorização dos rebanhos. Nesse processo, as tropas migraram para o interior do país, expandindo a criação nas direções do Centro-Oeste e Norte.

As tropas de muares eram criadas majoritariamente na região sul do Brasil, então, esses animais percorriam um caminho longo e muito difícil até chegarem aos locais de demanda, que eram principalmente as províncias de São Paulo e Minas Gerais. Com o intuito de facilitar a condução dos animais, foi criada uma rota chamada "Caminho das Tropas", que ligava as regiões sul e centro-sul do território brasileiro (SUPRINYAK, 2008).

Na região sul do Brasil, nos atuais estados do Paraná e Santa Catarina, ocorreu uma mesclagem entre os cavalos vindos de São Paulo e cavalos descendentes de animais extraviados da viagem de Cabeça de Vaca. De maneira muito rápida a criação de cavalos no Rio Grande do Sul ganhou notoriedade e fez do estado um fornecedor de equídeos para as demais regiões do Brasil, destacando-se a importância do comércio de cavalos envolvendo vendedores e compradores de diversas regiões do território nacional nas feiras, merecendo destaque a tradicional feira de Sorocaba. Estas feiras desempenharam papel relevante na formação da infraestrutura do Brasil colonial, já que foi o comércio dos rebanhos bovino e equídeo que contribuíram para conectar as regiões e manter o país interligado (LIMA et al., 2006).

Relatos de Langsdorff (SILVA, 1997) reiteram a visão do autor mencionado anteriormente, sobre a importância das tropas de muares no território nacional e seu protagonismo nas atividades de abastecimento. Nos relatos mencionados podem ser encontradas várias citações em relação às tarefas desenvolvidas pelas tropas. Em sua expedição ao Brasil entre os anos de 1824 a 1829, o médico alemão naturalizado russo percorreu mais de dezesseis mil quilômetros pelo interior do país, fazendo registros de diversos aspectos de sua natureza e sociedade. Foi relatado por ele em relação às tropas:

[...] diariamente chegam tropas trazendo açúcar e mercadorias; às vezes, num dia, chegam 1.000 mulas. A principal fonte de alimentação aqui é a criação de gado. As mulas hoje estão mais caras aqui do que no Rio de Janeiro. Um animal de montaria custa 50; um animal de carga, entre 30 e 40 [...] p 25

[...] Ainda antes de chegarmos à cidadezinha, vimos milhares de mulas, que, nesta época do ano, são trazidas para cá de Curitiba e de outras partes do sul da província e vendidas. Trata-se de uma espécie de mercado anual de animais que nasceu espontaneamente e que agora se constitui na principal fonte de sustento e alimentação da população local. Aqui se reúnem compradores de regiões vizinhas e distantes, inclusive de Minas, e daqui se levam tropas de mulas jovens para quase todas as regiões do Brasil. O preço do dia era 2.600 réis por mula e, no atacado, era de 3.300 réis. Na verdade, essa atividade comercial requer grandes extensões de pastos, abertos e fechados [...] p 66 


\section{Características dos muares: diferenças entre as espécies progenitoras}

De acordo com trabalho de Pereira Neto et al. (2014), o produto do cruzamento entre o Equus caballus e Equus asinus são animais híbridos chamados muares, animais de grande popularidade no meio rural e urbano devido à sua rusticidade e vigor físico. Como são indivíduos resultantes do cruzamento entre espécies com número de cromossomos diferentes, já que a égua possui 64 cromossomos e o jumento 62, os muares apresentam número ímpar de cromossomos, sendo 63, e tendem a nascer estéreis.

Segundo Silva (2011) os muares são animais imbatíveis na eficiência com que se locomovem ao longo de trilhas estreitas, sinuosas, pedregosas, acidentadas e íngremes em região de montanhas. Ribeiro et al. (2004) compartilham da mesma opinião do autor citado anteriormente relatando o destaque dos muares em atividades onde se avalia o andamento e as provas de resistência, conhecidas como cavalgadas.

Os muares se sobressaem em relação aos asininos devido ao porte maior, herdado da espécie materna e possuem maior destreza e prudência em ambientes inóspitos do que os equinos, por serem animais mais atentos, característica herdada da espécie paterna. Esses animais, de acordo com Araújo et al. (2014) têm maior capacidade de sobrevivência em ambientes adversos e apresentam maior resistência ao trabalho.

A Associação Brasileira de Criadores de Jumento Pêga relata várias características dos muares de acordo com os sentidos desses animais. A audição é um sentido extremamente sensível e muito desenvolvido nos muares. Em relação à visão os muares são mais atentos e perceptíveis do que os asininos. O olfato não é um sentido muito aguçado, visto que tanto asininos quanto muares podem ingerir a campo alimentos mais grosseiros em relação àqueles selecionados pelos equinos durante o pastejo. Os asininos e muares são poucos seletivos na aceitação de alimentos, ingerindo alimentos com sabor adocicado, adstringente e salgado. Sobre o tato é possível destacar a extrema sensibilidade dos muares, através dos cascos, que podem evitar situações de perigo ao animal e ao cavaleiro em terrenos sinuosos, o que reduz o risco de acidentes (SILVA, 2011).

Devido principalmente à sensibilidade dos muares por meio dos cascos, esses animais são utilizados também como atletas em diversas modalidades de provas, destacando-se aquelas onde se avalia o andamento e as provas de resistência, conhecidas como cavalgadas (PEREIRA NETO et al., 2014).

\section{Principais raças utilizadas nos cruzamentos}

Para a produção dos muares, várias raças de asininos e equinos podem ser utilizadas nos cruzamentos, de acordo com a finalidade que o híbrido será destinado. Podem ser obtidos animais

para trabalho, andamento e beleza (ARAÚJO et al., 2014). O sucesso na produção de muares 
depende do cruzamento entre animais com alto potencial genético, juntamente a outros fatores como idade e capacidade de reprodução dos animais utilizados no cruzamento (ROSSI, et al., 2016).

Normalmente é realizado o cruzamento entre a fêmea equina e o macho asinino, resultando no animal denominado muar. Porém, também pode ser feito o cruzamento utilizandose a fêmea asinina e o macho equino, resultando num híbrido denominado bardoto. No entanto, essa segunda opção de cruzamento é menos usual, visto que este animal herda o corpo da espécie materna e as extremidades da espécie paterna, sendo um animal com menor porte e menos elegante do que os muares, que, ao contrário, herdam o corpo da égua, de maior porte, e extremidades dos jumentos (AGUILAR, 2010).

As principais raças de asininos usadas na formação de muares são; o jumento Paulista ou Brasileiro, o jumento Pêga e o jumento Nordestino. É importante ressaltar que nem sempre existiram jumentos no país. Os asininos chegaram ao Brasil com os colonizadores portugueses, juntamente aos equinos. Dessa forma, se formou em território nacional a raça chamada Nacional ou Paulista. Esta raça que, como o nome já diz, é de origem do estado de São Paulo. Há uma semelhança com a raça Pêga em relação à aptidão para o trabalho, a altura, e o lombo curto e musculoso. Os animais dessa raça podem ser utilizados para montaria, carga ou tração (McMANUS et al., 2010), (REDAÇÃO RURAL NEWS, 2015).

A raça Pêga é considerada genuína para o andamento, que gera animais marchadores quando cruzada com raças equinas que também se destinam a essa finalidade. É um animal versátil que pode ser destinado a transporte de cargas, preparo do solo, trabalho com bovinos, cavalgadas, provas funcionais, concursos de marcha, dentre muitas modalidades A raça Pêga atualmente é a mais utilizada na formação de animais para sela (McMANUS et al., 2010), (SILVA, 2011).

Sobre o jumento Nordestino, é um dos animais que mais prestam serviços nessa região do país. É um animal pouco musculoso, se comparado a outras raças. São utilizados para montaria e para o transporte de carga, visto que têm grande resistência (McMANUS et al., 2010).

Em relação às raças das éguas a serem utilizadas nos cruzamentos, há grande diversidade nas possibilidades, de acordo com o que se busca do animal. A raça de éguas Quarto de Milha tem sido muito utilizada no cruzamento com asininos para a produção de muares. Essa raça foi a primeira a ser desenvolvida na América, e foi formada nos Estados Unidos aproximadamente no ano de 1600. Os animais Quarto de Milha são compactos, com músculos fortes, têm habilidade de correr distâncias curtas mais rapidamente do que outras raças. Esse animal é especialista no trabalho com bovinos e é considerado versátil, dócil, rústico e inteligente. Devido às 
características mencionadas, éguas dessa raça cruzadas com asininos produzem muares extremamente hábeis para a lida com bovinos, e alta resistência física (ABQM, 2016).

A raça Mangalarga Marchador também tem sido amplamente usada para a produção de muares. De acordo com Gonçalves et al. (2012) é a raça equina brasileira mais numerosa e está distribuída em todo o país. Originária do sul de Minas Gerais, o Mangalarga Marchador apresenta como característica padrão a marcha, que é um andamento natural e simétrico, com apoios alternados dos bípedes laterais e diagonais, intercalados por momentos de tríplice apoio. Esses movimentos fazem com que o andamento seja suave e confortável ao cavaleiro. Além dessa característica principal, essa raça também apresenta temperamento ativo e dócil, resistência, inteligência e rusticidade. Devido às características mencionadas, muares filhos de éguas dessa raça são muito valorizados pelo andamento marchado, e são considerados excelentes animais de sela (ABCCMM, s. d.), (SANTIAGO, et al., 2014).

Outra raça de éguas muito utilizadas no cruzamento com asininos é a raça Campolina. Esta é uma raça de origem nacional de equinos marchadores, proveniente do estado de Minas Gerais e começou a ser selecionada por volta de 1870. A raça apresenta porte nobre, formas harmoniosas, traços curvilíneos e estrutura óssea muscular que favorece o andamento marchado. Sua funcionalidade pode estar baseada na harmonia das medidas e nas proporções lineares de seu corpo. Na produção de muares resultam em animais de porte grande, fortes e marchadores (ABCCC, s. d.), (LUCENA et al., 2016).

\section{Variáveis relacionadas à resistência dos muares}

As cavalgadas de longa distância são cada vez mais populares em várias regiões do país, principalmente no interior do Brasil. Nessas circunstâncias os animais utilizados passam por uma prova de resistência que os submetem a exercícios de baixa intensidade e longa duração (RIBEIRO et al., 2004). Em vários municípios, principalmente no interior do país, as cavalgadas acontecem várias vezes ao ano, e há uma tendência cada vez mais frequente de se utilizar muares em marchas longas, em detrimento dos equinos. Há um grande senso empírico de que os muares são mais resistentes do que os equinos ao exercício físico, e algumas análises de constituintes séricos podem provar se a hipótese é ou não verdadeira. Todavia, há dificuldades na realização desses experimentos no que diz respeito à tentativa de se estipular valores de referência para tais avaliações, devido às diferenças em intensidade e duração do exercício ao qual o animal está sendo submetido, principalmente no caso dos muares, em que há falta de valores de referência, (PEREIRA NETO et al., 2013; RIBEIRO et al., 2004). De acordo com Lindner (2000), a concentração plasmática de lactato apresenta forte correlação com o desempenho esportivo dos equinos, sendo um dos parâmetros mais utilizados para determinar a intensidade dos exercícios 
de treinamento e para monitorar o condicionamento físico de equinos em treinamento, visto que a enzima lactato desidrogenase (LDH) tem concentração elevada nas lesões musculares. Em trabalho realizado por Santiago et al., (2013), nos testes realizados com equinos de concurso completo de equitação (CCE) foi avaliado a hematologia e a bioquímica sérica dos animais em treinamento. Durante testes de esforço incremental em esteira ergométrica de alta velocidade, na etapa de galopes, a concentração plasmática de lactato dos equinos acompanhou o aumento na intensidade do exercício, atingindo valores máximos a 8,0 metros por segundo. Entretanto, no segundo teste, observou-se concentração máxima de lactato também aos 15 minutos de recuperação. No primeiro teste, os equinos de dois grupos experimentais realizaram, em média, três minutos de galope, percorrendo 2.820 metros. No segundo teste, os equinos realizaram, em média, cinco minutos de galope, percorrendo 3.960 metros. Dessa forma, pôde-se observar o pico da concentração de lactato nos minutos iniciais do período de recuperação (SANTIAGO et al., 2013). No trabalho realizado por Pereira Neto (2013), sobre a atividade sérica das enzimas musculares em muares submetidos à prova de resistência, com a avaliação dos resultados obtidos foi possível observar que o exercício físico imposto influenciou de forma significativa a atividade sérica de lactato desidrogenase em muares. De acordo com Cardinet (1997), citado por Franciscato (2006) a Creatina quinase (CK) é a enzima mais amplamente utilizada para determinação de alterações musculares dos animais domésticos, e é considerada um indicador altamente sensível e específico de lesão muscular, já que os principais tecidos fontes dessa enzima são as fibras musculares. Não se constataram diferenças significativas entre os tempos de coleta avaliados e as concentrações séricas de creatina quinase (CK), dentre outras substâncias, observadas em muares, apesar das discretas variações verificadas. Tal fato pode, possivelmente, ser atribuído à maior adaptação destes animais ao tipo de prova realizada (RIBEIRO et al., 2004). Ainda, o resultado mencionado pode ter sido verificado pelo fato de que a CK é uma enzima de rápida liberação na circulação. (PEREIRA NETO 2013). Segundo publicação de Pereira Neto (2013) a avaliação das atividades séricas de lactato desidrogenase e creatina quinase (dentre outros elementos) frente ao exercício caracterizou-se como um grande desafio devido à diversidade na literatura consultada referente aos valores de repouso e valores registrados após a realização de uma atividade física, principalmente em se tratando de muares devido à escassez de dados.

\section{Importância dos muares para o agronegócio}

A equideocultura atualmente representa um setor da economia que movimenta milhões de reais por ano, e existem no mercado animais cada vez melhores geneticamente, capazes de alcançar altos valores em comercializações (COELHO;OLIVEIRA, 2008). 
Devido às características anatômicas adquiridas em sua evolução, os equídeos têm grande quantidade de funções para o ser humano (SANTIAGO, et al., 2014). Dentre essas funções, as cavalgadas são cada vez mais populares em várias regiões do país, principalmente no interior. Nessas circunstâncias os animais utilizados passam por uma prova de resistência que os submetem a exercícios de baixa intensidade e longa duração (RIBEIRO et al., 2004). No estado de Goiás as cavalgadas acontecem várias vezes ao ano, e há uma tendência cada vez mais frequente de se utilizar muares em marchas longas, em detrimento dos equinos devido ao senso empírico de que os muares são mais resistentes, por isso, esses animais estão cada vez mais valorizados (PEREIRA NETO, et al., 2014).

O complexo do agronegócio "equino" nacional movimenta aproximadamente R \$ 7,5 bilhões e gera cerca de 3,2 milhões de empregos diretos e indiretos. O equino, no aspecto econômico, desempenha as funções de sela, carga e tração. Destacam-se também no agronegócio equino os vários fornecedores de insumos, produtos e serviços para a criação, como medicamentos, rações, selas e acessórios, ferrageamento, veterinários, treinadores, transporte de equinos e, ensino e pesquisa (ALMEIDA;SILVA, 2010).

Diferentemente de muitas atividades agropecuárias, o agronegócio do cavalo (como é chamado, mas também inclui os muares e asininos) não se enquadra em uma estrutura padrão de cadeia produtiva linear. $\mathrm{O}$ que acontece é que existe uma série de cadeias emaranhadas que se interligam de alguma forma e se influenciam. É necessário que haja articulações entre setores, entre a agropecuária e a indústria para a formação do chamado agronegócio do cavalo, que apresenta grandes particularidades em relação a outros setores (LIMA et al., 2006). Essa teoria de cadeia interligada é demonstrada na figura 2.

Figura 2. Configuração do complexo do agronegócio do cavalo

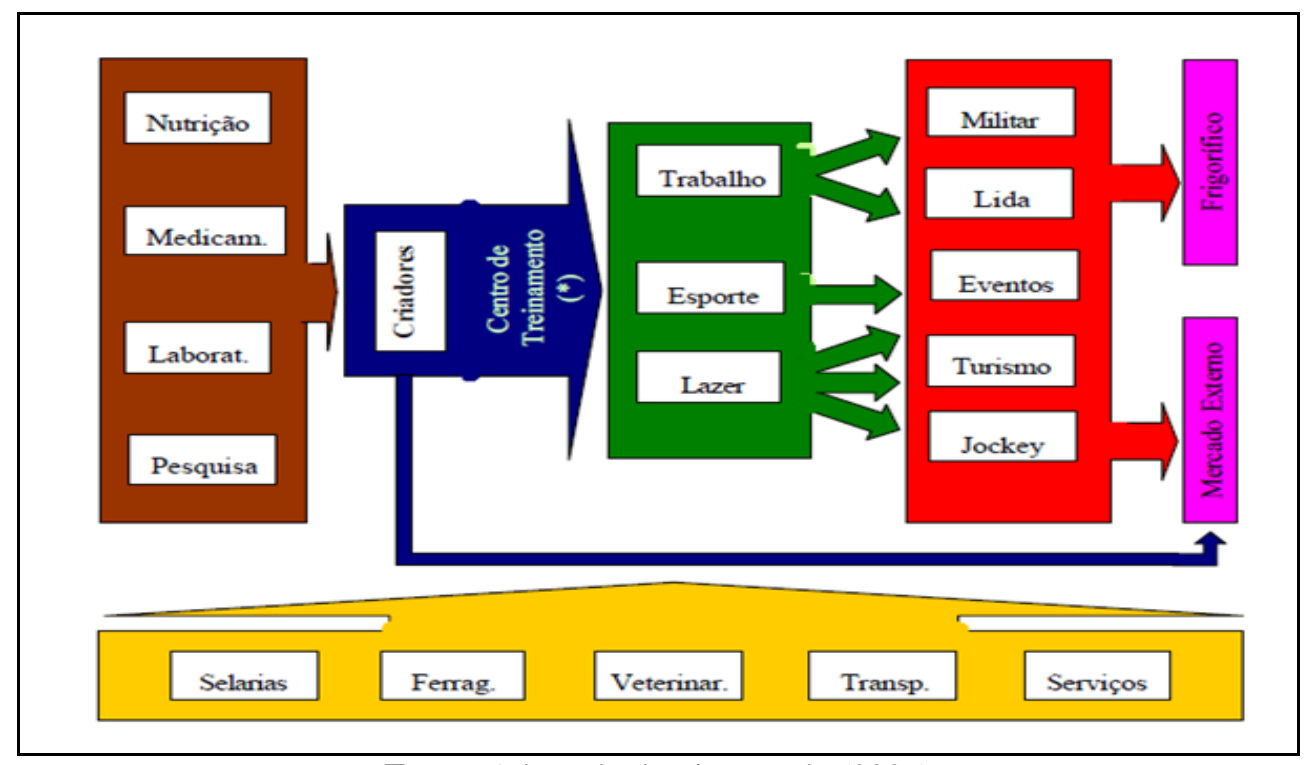

Fonte: Adaptado de Lima et al., (2006) 
Em se tratando dos muares, especificamente, segundo Haddad (2008), o mercado já era crescente e muito promissor, justamente por abranger vários setores, como, animais de tração, apartação de bovinos, trabalho diário em propriedades rurais, provas funcionais, esporte, concurso de marcha e realização de cavalgadas. Ainda, há um nicho acima dos citados que é o da seleção genética, sendo um excelente mercado a comercialização de cobertura de animais de alto valor genético. Esse mercado se torna muito importante principalmente em relação aos animais destinados à prática de esportes e provas funcionais, visto que têm a necessidade de serem melhor identificados quanto à sua descendência, seja para a execução de registros quanto para aquisição e agregação de valor (COELHO;OLIVEIRA, 2008).

Os muares ganharam seu espaço na equideocultura por apresentarem resultados positivos em diversos segmentos. Os fatores que podem ter influenciado a mudança de visão em relação a esses animais, que há anos atrás eram até discriminados, são a representatividade das associações e sua idealização de leilões, e parcerias que surgiram com associações de criadores de cavalos, como a associação da raça Mangalarga Marchador, da Campolina, dentre outras parcerias. Ainda, devido à crença da sociedade de que esses animais são mais resistentes fisicamente do que os equinos, e visto que atualmente existem muares tão confortáveis ao andamento e considerados belos exemplares assim como os melhores equinos, muitas pessoas estão dando lugar aos muares em detrimento dos equinos (HADDAD 2008).

\section{CONSIDERAÇÕES FINAIS}

Está cada vez mais clara a importância que os muares apresentam para o cenário atual do agronegócio. Além de terem sido extremamente importantes para a formação e desenvolvimento desse país, esses animais passam por um período de grande valorização nos dias de hoje. Os criadores de cavalos e adeptos de atividades equestres, que há alguns anos atrás poderiam discriminar esses animais por serem mais rústicos, hoje os valorizam pelo mesmo motivo; além de estarem cada vez melhores geneticamente, desempenhando com louvor as atividades de sela, trabalho e tração, são considerados mais resistentes que os equinos para essas funções. Precisa-se ainda de muitos estudos para comprovar se burros e mulas realmente são mais resistentes do que cavalos e éguas. O que se pode ter certeza é que, independentemente do que fique comprovado cientificamente, os muares estão em alta na sociedade equestre, e contribuem muito com o faturamento do Brasil no chamado "agronegócio do cavalo". 


\section{REFERÊNCIAS}

ABCCC - ASSOCIAÇÃO BRASILEIRA DE CRIADORES DE CAVALO CAMPOLINA. Morfologia. s. d. Disponível em: http://www.campolina.org.br/portal/morfologia.php. Acesso em: 25 de setembro de 2016.

ABCCMM - ASSOCIAÇÃO BRASILEIRA DE CRIADORES DE CAVALO MANGALARGA MARCHADOR. Características da raça. s. d. Disponível em http://www.abccmm.org.br/caracteristicas-da-raca. Acesso em: 25 de setembro de 2016.

ABQM - ASSOCIAÇÃO BRASILEIRA DE CRIADORES DE CAVALO QUARTO DE MILHA. Quarto de Milha: o cavalo da família brasileira. Cartilha ABQM. 2016. Disponível em: http://www.abqm.com.br/documentos/institucional/abqm_cartilha.pdf.Acesso em: 25 de setembro de 2016.

AGUILAR, R. Dicas para começar e melhorar sua produção. Revista Globo Rural. On-line. Ed 296, 2010. Disponível em: http://revistagloborural.globo.com/GloboRural/0,6993,EEC17053541489,00.html. Acesso em 27 de setembro de 2016.

ALMEIDA, F. Q.; SILVA, V. P. Progresso científico em equideocultura na 1a década do século XXI. Revista Brasileira de Zootecnia, v.39, p. 119-129, 2010. DOI: http://dx.doi.org/10.1590/S1516-35982010001300014.

ARAÚJO, A.L.et al.Tranquilização de asininos com acepromazina associada ou não ao diazepam. Arquivo Brasileiro de Medicina Veterinária e Zootecnia, v.66, n.1, p.109-115, 2014. DOI: http://dx.doi.org/10.1590/S0102-09352014000100016.

BRASIL. MINISTÉRIO DA AGRICULTURA, PECUÁRIA E ABASTECIMENTO. Equinos. Brasília, 2016. Disponível em: http://www.agricultura.gov.br/animal/especies/equídeos. Acesso em: 12 de abril de 2016.

COELHO, E. G. A; OLIVEIRA, D. A. A. Testes genéticos na equideocultura. Revista Brasileira de Zootecnia, v.37, suplemento especial p. 202-205, 2008. DOI:

http://dx.doi.org/10.1590/S1516-35982008001300023.

FARIA, M. D.et al. Biometria podal de equídeos (equus sp linnaeus, 1758) de tração. Ciência Animal Brasileira. Goiânia, v.15, n.2, p. 220-227. 2014. DOI: 10.1590/1809-6891v15i220318. URL: http://www.scielo.br/scielo.php?script=sci_arttext\&pid=S1809$\underline{68912014000200014 \& \operatorname{lng}=p t \& n r m=i s o \& t \operatorname{lng}=e n}$.

FAO - FOOD AND AGRICULTURE ORGANIZATION - United Nations. 2008. Disponível em: http://faostat.fao.org/site/573/default.aspx\#ancor. Acesso em: 17 de abril de 2016.

FRANCISCATO C., LOPES, S. T. A., VEIGA, A. P. M., MARTINS, D. B., EMANUELLI, M. P., OLIVEIRA, L. S. S. Atividade sérica das enzimas AST, CK e GGT em cavalos Crioulos. Pesquisa agropecuária brasileira. Brasília, v.41, n.10, p.15611565, out. 2006. DOI: http://dx.doi.org/10.1590/S0100-204X2006001000014. 
GONÇALVES, R.W.et al. Efeito da endogamia sobre características morfométricas em cavalos da raça Mangalarga Marchador. Arquivo Brasileiro de Medicina Veterinária e Zootecnia, v.64, n.2, p. 419-426, 2012. URL: http://www.scielo.br/pdf/abmvz/v64n2/a23v64n2.pdf.

IBGE, INSTITUTO BRASILEIRO DE GEOGRAFIA E ESTATÍSTICA. Censo Agropecuário 2006: Brasil, grandes regiões e unidades da federação. RJ-IBGE/90-13 (rev. 2009).

IBGE, INSTITUTO BRASILEIRO DE GEOGRAFIA A E ESTATÍSTICA. Produção da Pecuária Municipal. RJ, v. 39, p.1-63, 2011.

LIMA, R.A.S.; SHIROTA, R.; BARROS, G.S.C. Estudo do complexo do agronegócio cavalo. Piracicaba: ESALQ/USP, 2006.

LINDNER, A. Use of blood biochemistry for positive performance diagnosis on sports horses in practice. Revue de Médecine Vétérinaire, v.151, p.611-618, 2000. URL:

http://www.revmedvet.com/artdes-us.php?id=879.

LUCENA, J.E.C.et al. Caracterização morfométrica de fêmeas, garanhões e castrados da raça Campolina baseada em índices. Arquivo Brasileiro de Medicina Veterinária e Zootecnia, v.68, n.2, p. 431- 438, 2016. DOI: http://dx.doi.org/10.1590/1678-4162-8016.

HADDAD, L. F. A vez do Pêga. Revista Horse. n.3. Outubro de 2008.

McMANUS, C.et al. Jumentos no Brasil. INCT: Informação genético-sanitária da pecuária brasileira. 2010. Disponível em: http://inctpecuaria.com.br/images/informacoestecnicas/serie_jumentos.pdf. Acesso em: 24 de setembro de 2016.

PEREIRA NETO, E.et al.. Atividade sérica das enzimas musculares em muares submetidos à prova de resistência de $100 \mathrm{~km}$. Pesquisa Veterinária Brasileira. 33 (11):1385-1389, novembro 2013. URL: http://www.scielo.br/pdf/pvb/v33n11/v33n11a16.pdf.

PEREIRA NETO E.et al.Eritrograma em muares submetidos à prova de resistência de $100 \mathrm{Km}$. Revista Brasileira de Medicina Veterinária, v. 36, n. 2, p. 226-230, 2014. URL: http://www.rbmv.com.br/pdf_artigos/10-12-2014_17-47RBMV045.pdf.

RIBEIRO C.R.et al. Avaliação de constituintes séricos em equinos e muares submetidos à prova de resistência de 76km, no Pantanal do Mato Grosso, Brasil. Ciência Rural, v 34, p. 1081-1086, 2004. URL: http://www.scielo.br/pdf/cr/v34n4/a18v34n4.pdf.

REDAÇÃO RURAL NEWS. Principais raças de jumentos no Brasil. 2015. Disponível em: http://www.ruralnews.com.br/visualiza.php?id=388. Acesso em 17 de agosto de 2016.

ROSSI, R.et al. Effect of month of conception on fertility of mares inseminated with jackass sêmen. Arquivo Brasileiro de Medicina Veterinária e Zootecnia, v.68, n.1, p.57-65, 2016. DOI: http://dx.doi.org/10.1590/1678-4162-7549.

SANTIAGO, J.M.ET. Hematologia e bioquímica sérica de equinos de concurso completo de equitação em treinamento. Arquivo Brasileiro de Medicina Veterinária e Zootecnia. v 65, n.2, p.383-392, 2013. DOI: http://dx.doi.org/10.1590/S0102-09352013000200013. 
SANTIAGO, J.M.et al. Comparação entre as medidas morfométricas de equinos Mangalarga Marchador de marcha batida e marcha picada. Arquivo Brasileiro de Medicina Veterinária e Zootecnia, v.66, n.2, p. 635-639, 2014. DOI: http://dx.doi.org/10.1590/1678-41626870.

SILVA, A. L. F. Hábitos peculiares de comportamento dos asininos e muares. Associação Brasileira de Criadores de Jumento Pêga. 2011. Disponível em:

http://www.abcjpega.com.br/2011/11/habitos-peculiares-de-comportamento-dos-asininos-emuares/. Acesso em 28 abril de 2016.

SILVA, D. G. B.et al. Os Diários de Langsdorff [online]. Translation Márcia Lyra Nascimento Egg and others. Campinas: Associação Internacional de Estudos Langsdorff. Rio de Janeiro: Editora FIOCRUZ, 1997. 400 p. Vol. 2.URL: http://static.scielo.org/scielobooks/q5cc4/pdf/silva9788575412442.pdf.

SUPRINYAK, C. E. O mercado de animais de carga no centro-sul do Brasil imperial: novas evidências. Estudos Econômicos. [Online] vol.38, n.2, p.319-347. 2008. DOI:

http://dx.doi.org/10.1590/S0101-41612008000200005.

TORRES, A. P. Melhoramento dos rebanhos. $5^{\text {a }}$ ed. Nobel, 1981.

TORRES, A. P.; JARDIM, W. R. Criação do cavalo e outros equinos. $3^{\text {a }}$ ed. Nobel, 1992.

VIEIRA, E.R.et al. Caracterização da equideocultura no estado de Minas Gerais. Arquivo

Brasileiro de Medicina Veterinária e Zootecnia, v.67, n.1, p. 319-323, 2015. DOI:

http://dx.doi.org/10.1590/1678-7460. 
